\title{
Neuropsychological characteristics of Huntington's disease carriers: a double blind study
}

Nicole K Rosenberg, Sven Asger Sørensen, Anne-Lise Christensen

\begin{abstract}
A cohort of 33 people at risk for Huntington's disease (HD), applying for genetic testing, were tested with a battery of neuropsychological tests covering attentional, visuospatial, learning, memory, and planning functions. A psychiatric rating scale, SCL-90R, was also applied, mainly as a control, since cognitive dysfunction could be ascribed to functional disorders as well as neurodegenerative processes.

Self-rating did not indicate any psychiatric symptoms in carriers or noncarriers. However, significantly inferior cognitive functioning in the gene carriers was disclosed by the neuropsychological tests. Primarily, attentional, learning, and planning functions were affected. It is concluded that premorbid cognitive decline occurs in HD.
\end{abstract}

(f Med Genet 1995;32:600-604)

Huntington's disease (HD) is a neurodegenerative disorder with autosomal dominant inheritance and complete penetrance. The mean age of onset is between 35 and 44 years, leading to death after about 15 years. Clinical diagnosis is based on family history and onset of involuntary, choreiform movements. ${ }^{1}$

The HD gene was localised to the short arm of chromosome 4 by genetic linkage analyses of RFLPs ${ }^{2}$ making presymptomatic testing of at risk subjects possible by linkage analysis. Direct analysis of the gene became available when the mutation was identified as an unstable $(\mathrm{CAG})_{\mathrm{n}}$ trinucleotide repeat in the $5^{\prime}$ coding region of the HD gene. ${ }^{34}$

The main purpose of the present paper is to report on neuropsychological characteristics of the first 40 persons who requested a presymptomatic test for HD in Denmark. In several studies neuropsychological dysfunction has been found after the onset of $\mathrm{HD}^{5-7}$ increasing in severity as HD progresses. ${ }^{8}$

Identification of neuropsychological dysfunction in the premorbid mental state in persons at risk for $\mathrm{HD}$ can provide knowledge about the earliest effect of HD on cognition and thus about the relation between brain processes and behaviour. Marker analyses, and especially direct DNA analysis, have made this kind of investigation possible in a naturally blind setting. ${ }^{9-12}$ The findings of such studies differ concerning the presence of neuropsychological dysfunction. However, one of the most recent studies found "evidence of presymptomatic cognitive decline in HD". ${ }^{11}$

Closely related to the neuropsychological studies is the issue of presymptomatic and early psychiatric symptoms. ${ }^{13-15}$ The main finding in this area is that depression is common, but that severe psychiatric morbidity is seldom present in these stages of HD.

In our study, a battery of neuropsychological tests covering basic as well as more complex cognitive functions related to different parts of the brain was used. A self-rating scale for psychiatric symptoms was added mainly as a control, as neuropsychological dysfunction could be ascribed to psychiatric illness as well as neurodegenerative processes.

\section{Materials and methods}

The first Danish persons at risk for $\mathrm{HD}$ attending for genetic testing were consecutively included in a cohort of 40 subjects. The recommendations for procedure of genetic testing programmes were followed. ${ }^{16}$ The study was double blind. A clinical neurological examination was done by one of us (SAS) in all cases in order to exclude persons with symptoms of HD. Psychological tests and rating were administered (by the first author) before the DNA test was performed. Blindness to carrier status was broken several months after scoring of the psychological tests had been accomplished.

Three protocols were withdrawn owing to missing data. Fourteen persons, whose haplotypes were originally uninformative, were offered retesting of blood samples after introduction of the direct test method. Four persons declined and thus remained uninformative. Data from 19 non-carriers and 14 carriers were available for the comparative statistical analyses. Data from most of the neuropsychological test were missing for one carrier.

\section{SELF-RATING SCALE}

The Symptom Checklist - 90 items revised (SCL$90 R$ ), a self-rating scale providing quality and intensity of psychopathology, was used. Ninety items are rated from 0 ( $=$ not at all) through 1 (=a little bit), 2 (=moderately), and 3 (= quite a bit) to 4 (=extremely) and clustered to dimensions of psychopathology. ${ }^{17}$ 
NEUROPSYCHOLOGICAL TESTS OF ATTENTIONAL FUNCTIONS

Trailmaking $A$ and $B$ measure psychomotor speed, concentration, visual scanning, visuomotor tracking, and flexibility in sequencing. In part A lines are drawn to connect consecutively numbered circles. In part B similar circles alternate between numbers and letters. Response speed as well as numbers of errors are registered. ${ }^{18}$

Symbol Digit Modality Test (SDMT) measures attention, visual scanning, and visuomotor speed. A row of digits from 0 to 9 is presented, together with one symbol for each digit. Within 90 seconds digits and symbols have to be paired. Results are stated as the number of correct digits written within the time limit. ${ }^{18}$

Block Design (a subtest of Wechsler Adult Intelligence Scale (WAIS) $)^{19}$ measures spatial organisation and visuomotor ability. Increasingly difficult square patterns are presented and, within given time limits, are to be reproduced using blocks. Results are stated as the total score and total time taken.

\section{NEUROPSYCHOLOGICAL TESTS OF LEARNING AND} MEMORY

Story Recall Test (Subtest of the Wechsler Memory Scale (WMS) $)^{20}$ measures verbal and logical memory. Two short texts are read to the proband, who is asked to repeat the stories immediately (WMS 1) and after one hour's delay (WMS 2). Results are stated as the average number of elements correctly recalled.

Word-picture association and "Pictogram" from Luria's Neuropsychological Investigation $(L N I)^{21}$ were used. In word-picture association, auditory learning by visual support is investigated using 10 cards with different pictures, presented together with an opposite, related or unrelated word. Immediately after the cards are shown and the word should be remembered; in the pictogram test the proband is asked to draw pictures in order to remember 14 words/sentences. Results are stated as number of correct answers on subsequently being shown the pictures.

California Verbal Learning Test $(C V L T)^{22}$ is a test of immediate and delayed recall of words, reactions to interference, and ability to categorise as a learning strategy. Sixteen items from four categories are presented as a shopping list and read five times. After each reading (trials 1-5) recall of the words is requested. Another 16 word list is read and reproduced (trial 6). Without repeating the first list it should be reproduced freely (trial 7) and then with categorisation as a support (trial 8). After 20 minutes, delayed reproduction is required as trials 9 and 10. Finally, passive recall is tested by requiring recognition of the original 16 words from a list of 64 words, read by the tester. Results are stated as number of words correctly recalled for each trial (trials 1-11), and number of clusters (two words within same category, mentioned successively).

Ruth Andersen's Visual Gestalts ${ }^{18}$ measures immediate and delayed recall of geometrical figures. The test requires reproduction by drawing of four geometrical figures. Results are stated as number of errors in immediate (part 1) and delayed reproduction (part 2).

\section{NEUROPSYCHOLOGICAL TESTS OF PLANNING}

Rupp's test (from LNI) ${ }^{21}$ requires continuing of a honeycomb pattern by drawing and thus maintaining a system of spatial relationships. Result is stated as correct (1) or incorrect (0). Modified Card Sorting Test (MCST) ${ }^{23}$ measures planning, sequencing, cognitive set shifting and maintenance, and ability to follow an inner plan in spite of conflicting external stimuli. Four reference cards, characterised by colour, form, and number of figures, are placed in front of the proband, who has to place a series of cards one by one under the reference cards. The rule for placing the cards must be inferred from the investigator's comments: right or wrong to each placement. Results are stated as number of falsely placed cards when going through each category twice with six cards correctly placed successively for each category. Tower of Toronto ${ }^{24}$ is a test of procedural learning and memory. It involves sequencing, planning, problem solving, and rule directed behaviour. Differently coloured discs (in part A three, in part $B$ four) are placed on the first of a row of three sticks. The test requires that the subjects move the discs to the last stick, using as few moves as possible, following explicit rules. Results are stated as number of moves to complete the tasks (part A can be solved in 7 moves, part $B$ in 15).

In the present study the Rorschach test ${ }^{25}$ was applied as a neuropsychological test. ${ }^{19}$ Ten cards with inkblots are presented with the instruction to say what the blot looks like. Results are stated as number of meagre protocols, that is, protocols with fewer than 12 answers, and number of protocols with more than five "Piotrowski's signs", ${ }^{26}$ which indicate dementia.

\section{DATA ANALYSES}

Non-parametric analyses were performed as appropriate, using the SPSS/PC.$+{ }^{27}$ Fischer's exact test was applied for nominal data and the Mann-Whitney U test was used for analyses of ordinal data. Spearman's rank order correlation was calculated between age and test performance. Significance level (alpha) was set to 0.05 two tailed for all comparisons.

\section{Results}

DEMOGRAPHIC CHARACTERISTICS

No difference between carriers and non-carriers in age, sex, or educational level was found (table 1).

\section{PSYCHIATRIC SYMPTOMS}

In table 2 SCL-90R scores are presented. Mean scores on all dimensions of pathology were between 0 and 1 (no problem and "a little bit") in carriers as well as non-carriers, indicating that intensity of self-reported psychiatric symptoms was far below the levels corresponding to a psychiatric case. 
Table 1 Characteristics of 19 non-carriers and 14 carriers applying for genetic testing for $H D^{*}$

\begin{tabular}{lll}
\hline & Non-carrier & Carrier \\
\hline Age: mean (range) & $33 \cdot 6 \mathrm{y}$ & $30 \cdot 2 \mathrm{y}$ \\
Males & $(18-53)$ & $(24-48)$ \\
Females & 5 & 5 \\
$\begin{array}{l}\text { Duration of education after } \\
\text { elementary school }\end{array}$ & 14 & 9 \\
$\quad$ & \\
No further education & 5 & 5 \\
Apprentice/<1 y & 2 & 4 \\
1-3 y & 7 & 3 \\
$>3$ y & 5 & 2 \\
\hline
\end{tabular}

*No differences were statistically significant.

NEUROPSYCHOLOGICAL FUNCTIONS

In contrast to the SCL-90R, neuropsychological tests showed several significant differences between carriers and non-carriers (table 3). Psychomotor speed, attention, and concentration were lowered in the more complex tests.

Different aspects of the verbal learning and memory processes were assessed by the categorial learning test (CVLT), the word-picture association and Pictogram, the story recall test (WMS), and CVLT. The difference in learning profiles for words, measured by CVLT (figure),

Table 2 SCL-90R dimensions of 19 non-carriers and 14 carriers of the gene for HD

\begin{tabular}{|c|c|c|c|c|c|}
\hline & \multicolumn{2}{|c|}{ Non-carrier } & \multicolumn{2}{|c|}{ Carrier } & \multirow{2}{*}{$\begin{array}{l}\text { Difference } \\
\text { (Mann-Whitney } \\
\text { U test) }\end{array}$} \\
\hline & Mean & $S D$ & Mean & $S D$ & \\
\hline Somatisation & 0.5 & 0.6 & 0.5 & 0.5 & NS \\
\hline Obsessive-compulsive & 0.5 & $0 \cdot 8$ & $0 \cdot 7$ & 0.9 & NS \\
\hline Interpersonal sensitivity & 0.5 & 0.6 & 0.6 & 0.5 & NS \\
\hline Depression & $0 \cdot 4$ & 0.6 & $0 \cdot 7$ & 0.6 & NS \\
\hline Anxiety & 0.5 & 0.7 & $0 \cdot 7$ & 0.6 & NS \\
\hline Aggression/hostility & 0.5 & $0 \cdot 8$ & $0 \cdot 4$ & $0 \cdot 5$ & NS \\
\hline Phobia & $0 \cdot 1$ & $0 \cdot 3$ & $0 \cdot 3$ & 0.5 & NS \\
\hline Paranoia & $0 \cdot 4$ & 0.6 & $0 \cdot 3$ & $0 \cdot 3$ & NS \\
\hline Psychosis & 0.3 & 0.5 & 0.5 & $0 \cdot 3$ & NS \\
\hline
\end{tabular}

NS $=$ not significant.

Table 3 Results of neuropsychological tests of 19 non-carriers and 13 carriers of the gene for $H D$

\begin{tabular}{|c|c|c|c|c|c|}
\hline \multirow[t]{2}{*}{ Tests } & \multicolumn{2}{|c|}{ Non-carriers } & \multicolumn{2}{|c|}{ Carriers } & \multirow{2}{*}{$\begin{array}{l}\text { Difference } \\
\text { (Mann-Whitney } \\
\text { U test) }\end{array}$} \\
\hline & Mean & $S D$ & Mean & $S D$ & \\
\hline SDMT & $50 \cdot 6$ & $12 \cdot 5$ & $41 \cdot 7$ & $12 \cdot 5$ & NS \\
\hline Trail making $\mathrm{A}^{*}$ & $34 \cdot 9$ & $6 \cdot 6$ & $47 \cdot 7$ & 20.9 & NS \\
\hline Trail making B* & $72 \cdot 4$ & $22 \cdot 2$ & 123.6 & $90 \cdot 9$ & 0.01 \\
\hline Block design, points* & $41 \cdot 1$ & $6 \cdot 3$ & 35.9 & $5 \cdot 6$ & 0.02 \\
\hline Block design, speed* & 309.6 & $150 \cdot 7$ & $416 \cdot 4$ & $124 \cdot 2$ & 0.04 \\
\hline WMS 1 & $9 \cdot 8$ & $3 \cdot 2$ & 6.9 & $4 \cdot 3$ & 0.05 \\
\hline WMS 2 & $7 \cdot 5$ & $2 \cdot 6$ & $4 \cdot 9$ & $3 \cdot 3$ & 0.03 \\
\hline Visual gestalts 1 & $2 \cdot 1$ & $2 \cdot 4$ & $6 \cdot 4$ & $7 \cdot 4$ & 0.05 \\
\hline Visual gestalts 2 & $6 \cdot 6$ & 6.9 & $8 \cdot 3$ & $8 \cdot 2$ & NS \\
\hline Word-picture association & $9 \cdot 2$ & $1 \cdot 0$ & $7 \cdot 6$ & $2 \cdot 5$ & NS \\
\hline Pictogram & $10 \cdot 7$ & $2 \cdot 5$ & $7 \cdot 9$ & $3 \cdot 5$ & 0.04 \\
\hline CVLT, number of clusters & $48 \cdot 8$ & $14 \cdot 5$ & $26 \cdot 2$ & $24 \cdot 9$ & 0.003 \\
\hline MCST (errors) & $10 \cdot 2$ & $8 \cdot 1$ & $8 . \overline{9}$ & $5 \cdot 8$ & NS \\
\hline Tower At & $12 \cdot 6$ & $18 \cdot 4$ & $15 \cdot 1$ & $22 \cdot 0$ & NS \\
\hline Tower B & $22 \cdot 2$ & $3 \cdot 8$ & $27 \cdot 8$ & $12 \cdot 0$ & NS \\
\hline
\end{tabular}

* Carriers: 14 observations.

†Tower A was given up by 1 non-carrier and 1 carrier.

†Tower A was given up by 1 non-carrier and 1 carrier.

NS = not significant.

Table 4 Rorschach test of 19 non-carriers and 13 carriers of the gene for $H D$

\begin{tabular}{|c|c|c|c|c|c|}
\hline \multirow[t]{2}{*}{ Item } & \multicolumn{2}{|c|}{ Non-carrier } & \multicolumn{2}{|c|}{ Carrier } & \multirow{2}{*}{$\begin{array}{l}\text { Difference } \\
\text { (Fisher's exact } \\
\text { test) }\end{array}$} \\
\hline & No & $\%$ & No & $\%$ & \\
\hline $\begin{array}{l}\text { Meagre protocol } \\
\text { Protocol with Piotrowski's } \\
\text { signs }>5(\%)\end{array}$ & $\begin{array}{l}5 \\
0\end{array}$ & $26 \cdot 3$ & $\begin{array}{r}10 \\
5\end{array}$ & $\begin{array}{l}71.4 \\
35.7\end{array}$ & $\begin{array}{l}0.01 \\
0.006\end{array}$ \\
\hline
\end{tabular}

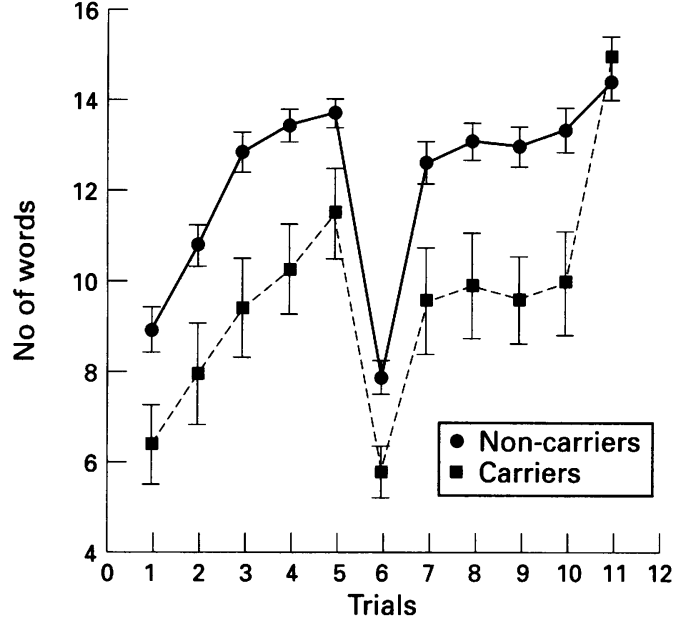

The learning curves of carriers and non-carriers of the HD gene for the CVLT (16 words per trial). The numbers of retained words per trial and SEM are shown. Differences between carriers and non-carriers are significant with $t$ test at level $p=0.01$ (trials $1-4,6,9,10$ ) and level $p=0.05$ (trials 5,7,8). Trial 6 is reproduction of an alternative list of 16 words. The difference in trial 11 (recognising) is not significant.

shows that the gene carriers never attained the same level as the non-carriers, when active reproduction of words was required. $\mathrm{Re}-$ cognition of words, however, was equal for the two groups. Gene carriers used clustering of words as a support to the learning process in CVLT to a lesser degree than non-carriers (shown in table 3), indicating lowered ability to facilitate learning by categorisation. In the pictogram test, visuomotor support in learning and retrieval of words/sentences had less effect in carriers than in non-carriers. Story recall was similarly severely impaired in gene carriers (WMS, table 3).

The visual memory test (Visual gestalts, table 3) showed that learning to reproduce a geometrical pattern was impaired in the gene carriers, whereas there was no significant difference in delayed recall.

Planning, sequencing, and distractability were measured by the card sorting test (MCST), the Tower of Toronto (table 3), and Rupp's test (the honeycomb pattern test). No differences were found in MCST. The Tower test was given up by many subjects, mostly carriers, and no differences were found for the remaining subjects. The honeycomb pattern test was correctly solved by $89 \%$ of the noncarriers and $50 \%$ of the carriers ( $\chi^{2}$ test, $\mathrm{p}<0 \cdot 01$ )

Results of the Rorschach test are shown in table 4. Significantly more protocols of the carriers were meagre, indicating lowered energy and processing ability. No non-carriers compared to $35 \cdot 7 \%$ of the carriers fulfilled the criteria for dementia. ${ }^{26}$

\section{Discussion}

As in most published investigations comparable to ours, the number of carriers was fewer than half, partially because of the age specific risk. Significantly more females than males were 
applicants, which might be because of sex differences in applying for medical support. Many of the carriers must be close to age of onset as mean age was about 30 years.

Psychiatric morbidity was not reported at the time of the investigation. Nearly half of the subjects, however, reported one or several past depressive episodes, the severity of which were not systematically investigated. This corresponds with findings in recent studies. Folstein $e t \mathrm{al}^{28}$ found depression including dysthymia in $38 \%$ of persons at risk for HD. In another study $35 \%$ of HD patients with recent onset of HD symptoms had a history of depression. ${ }^{29}$ Jensen et $a l^{13}$ concluded that severe psychiatric disorders in diagnosed HD patients are most likely aetiologically related to HD. Baxter et $a l^{14}$ and Watt and Seller, ${ }^{15}$ however, concluded that asymptomatic carriers have fewer functional psychiatric disorders than expected. Watt and Seller ${ }^{15}$ also hypothesised that psychiatric disorders including depression in undiagnosed at risk subjects is related to psychosocial factors and thus should be found equally often among carriers and non-carriers in premorbid stages.

As in the study of Diamond et al, ${ }^{11}$ our study showed no difference between carriers and noncarriers on the psychiatric rating scale, while the neuropsychological tests showed that the gene carriers were significantly more impaired with regard to cognitive function than the noncarriers. Not only did more than half of the neuropsychological tests show a significantly poorer performance in carriers than in noncarriers, but all the remaining tests showed a difference in this direction, albeit not statistically significant (table 3 ).

$\mathrm{HD}$ involves a neurodegenerative process in which rapidly developing atrophy of the caudate nucleus and reduced glucose metabolism in the basal ganglia have been found by neuroimaging methods. ${ }^{3031}$ Neuropsychological studies also point to impairment of cognitive functions related to the basal ganglia. ${ }^{5-7}$ In accordance with these observations, difficulties in psychomotor speed and attentional functions were found in the present study.

In our study several aspects of the learning and immediate reproduction process and delayed verbal memory were impaired. Huber and Paulson, ${ }^{8}$ among others, found that in the early stages of $\mathrm{HD}$ memory acquisition and retrieval are normal, but decline in later stages. Rothlind et $a l^{12}$ also found unimpaired verbal learning and memory functions in marker positive subjects with a mean age of about 30, except for one woman who shortly afterwards developed clinical manifestations of HD. Diamond et $a l^{11}$ found that probable gene carriers were inferior to probable non-carriers on tests involving learning and memory. Pillon et $a l^{32}$ also found deficient memory in HD patients but related this to inefficient planning. Our findings of impaired memory could be ascribed to the impaired attentional abilities. Planning problems might play a role too, as the gene carriers displayed impaired functions ascribed to the frontal lobes, to perform logically and fluently, and to categorise, in two tests: CVLT and Rupp's tests. These tests require complex frontal functions despite appearing simple and therefore not being stress provoking. In contrast, the Tower of Toronto was not informative perhaps because many people found the task too complicated. Abandoning of the task was mainly seen in carriers, but could be related to stress as well as specific cognitive deficits. The administration of the modified card sorting test, however, might be too supportive to detect problems related to the frontal lobes. Results of the non-carriers on the neuropsychological tests were very close to standard norms in most tests. In the tests requiring concentration (for example, WMS) where results of the carriers were lower than norms, the carriers still had lower scores, indicating that stress related to the situation might influence the result, but that neuropsychological deficits explain the difference between carriers and non-carriers.

Given that cognitive impairment is present before onset of clinical manifestations of HD, the group of gene carriers should include subjects with different degrees of cognitive dysfunction dependent on time from onset. Age of onset varies, but a negative correlation between age and test score would suggest that cognitive decline in carriers explains the difference between groups. Although correlations between age and test scores were not statistically significant in any of the groups, negative correlations between all tests and age were closer to a statistically significant level in the carrier group than in the non-carrier group.

As the scores on SCL-90R were very low, differences could not be ascribed to depression or other types of functional psychopathology. We therefore conclude that cognitive impairment occurs before the onset of choreic movements and is unrelated to psychiatric symptoms in carriers of the HD gene.

This work was supported by grants from Folmer og Ingeborg Lüttichaus Familiefond and Direktør Ib Henriksens Fond. We are grateful to Dr Thomas Teasdale for his invaluable advice.

1 Harper P. The epidemiology of Huntington's disease. In Harper P, ed. Huntington's disease. London: Saunders, 1991.

2 Gusella JF, Wexler NS, Conneally PM, et al . A polymorphic DNA marker genetically linked to Huntington disease. Nature 1983;306:234-8.

3 The Huntington's Disease Collaborative Research Group. A novel gene containing a trinucleotide repeat that is expanded and unstable on Huntington's disease chromosome. Cell 1993;72:971-83.

4 Nørremølle A, Riess O, Epplen JT, et al. Trinucleotide repeat elongation in the Huntington gene in Huntington disease patients from 71 Danish families. Hum Mol Genet 1993;2:1475-6.

5 Josiassen RC, Curry L, Roemer RA, DeBease C, Mancall EL. Patterns of intellectual deficit in Huntington's disease. f Clin Neuropsychol 1982;4:173-83.

6 Taylor HG, Hansotia P. Neuropsychological testing of Huntington's patients. F Nerv Ment Dis 1983;171:492-6.

7 Brandt J, Butters N. The neuropsychology of Huntington's disease. Trends Neurl Sci 1986;9:118-20.
randt

8 Huber SJ, Paulson GW. Memory impairment associated with progression of Huntington's disease. Cortex 1987;23: 275-83.

9 Jason GW, Pajurkova EM, Suchowersky O, et al. Presymptomatic neuropsychological impairment in Huntington's disease. Arch Neurol 1988;45:769-73.

10 Strauss ME, Brandt J. Are there neuropsychological manifestations of the gene for Huntington's disease in asymptomatic, at-risk individuals? Arch Neurl 1990;47: 905-8.

11 Diamond R, White RF, Myers RF, et al. Evidence of presymptomatic cognitive decline in Huntington's disease. $\mathcal{f}$ Clin Exp Neuropsychol 1992;14:961-75.

12 Rothlind JC, Brandt J, Zee D, Codori AM, Folstein S. Unimpaired verbal memory and oculomotor control in 
asymptomatic adults with the genetic marker for Huntington's disease. Arch Neurol 1993;50:799-802.

13 Jensen P, Sørensen SA, Fenger K, Bolwig TG. A study of psychiatric morbidity in patients with Huntington's disease, their relatives, and controls admissions to psychiatric hospitals in Denmark from 1969 to 1991. Br f sychiatry 1993;163:790-7.

14 Baxter LR Jr, Mazziotta JC, Pahl JJ, et al. Psychiatric, genetic, and positron emission tomographic evaluation of persons at risk for Huntington's disease. Arch Gen Psychiatry 1992;49:148-54.

15 Watt DC, Seller A. A clinico-genetic study of psychiatric disorder in Huntington's chorea. Psychol Med 1993;suppl 23:1-46.

16 Committee of representatives of the International Huntington Association and the World Federation of Neurdogy. Ethical issues policy statement on Huntington's disease molecular genetics predictive test. $\mathcal{J}$ Med Gemet 1990;27:34-8.

17 Derogatis LR, Lipman RS, Covli L, et al. The SCL-90: an outpatient psychiatric rating scale. Psychopharmacol Bull outpatient psychir

18 Lezak M. Neuropsychological assessment. New York: Oxford University Press, 1983

19 Wechsler D. Wechsler Adult Intelligence Scale Manual. New York: The Psychological Corporation, 1981.

20 Wechsler D. A standardized memory scale for clinical use. f Psychol 1994;19:87-95.

21 Christensen AL. Luria's neuropsychological investigation. Copenhagen: Munksgaard, 1974.
22 Crosson B, Novack TA, Trennery X, et al. California verbal learning (CVLT) performance in severely head-injured learning (CVLT) performance in severely head-injured and neurogically normal

psychol 1988;10:754-68.
23 Nelson HE. A modified card sorting test sensitive to frontal lobe defects. Cortex 1976;12:313-24.

24 Saint-Cyr JA, Taylor AE, Lang AE. Procedural learning and neostriatal dysfunction in man. Brain 1988;111 941-59.

25 Exner JE. The Rorschach. A comprehensive system. Vol 1. Basic foundations. New York: John Wiley, 1986.

26 Piotrowski Z. Positive and negative Rorschach organic reactions. Rorschach Research 1940;4:147-51.

27 Norusis MJ. SPSS/PC + for the IBM PC/XT/AT. Chicago: SPSS Inc, 1986.

28 Folstein SE, Abbot MH, Chase GA. The association of affective disorder with Huntington's disease: in a case series and in families. Psychol Med 1983;13:537-42.

29 Folstein SE. Huntington's disease: a disorder of families. Baltimore: Johns Hopkins University Press, 1989.

30 Mazziota JC, Phelps ME, Pahl JJ. Reduced cerebral glucose metabolism in asymptomatic subjects at risk for Hunmetabolism in asymptomatic subjects at risk for
tington's disease. $N$ Engl $f$ Med 1987;316:357-62.

31 Grafton ST, Mazziotta JC, Pahl JJ, et al. Serial changes of cerebral glucose metabolism and caudate size in persons cerebral glucose metabolism and caudate size in persons
at risk for Huntington's disease. Arch Neurol 1992;49: at risk for

32 Pillon B, Deweer B, Agid Y, Dubois B. Explicit memory in Alzheimer's, Huntington's, and Parkinson's diseases. Arch Neurol 1993;50:374-9. 